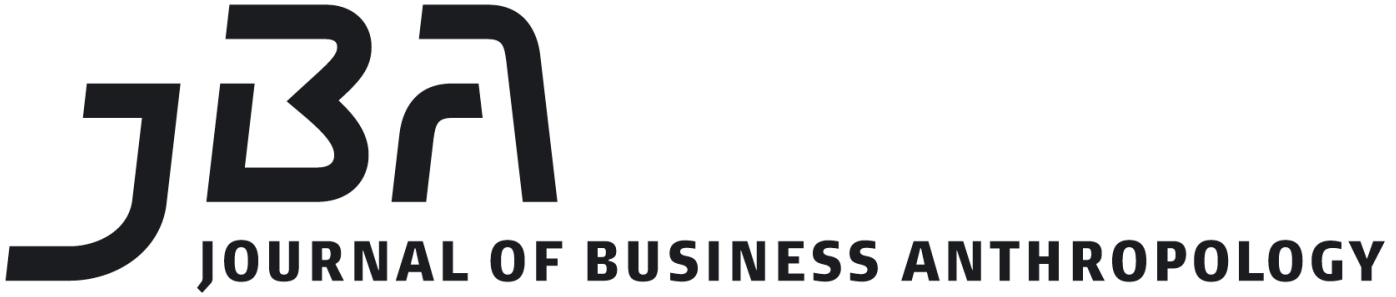

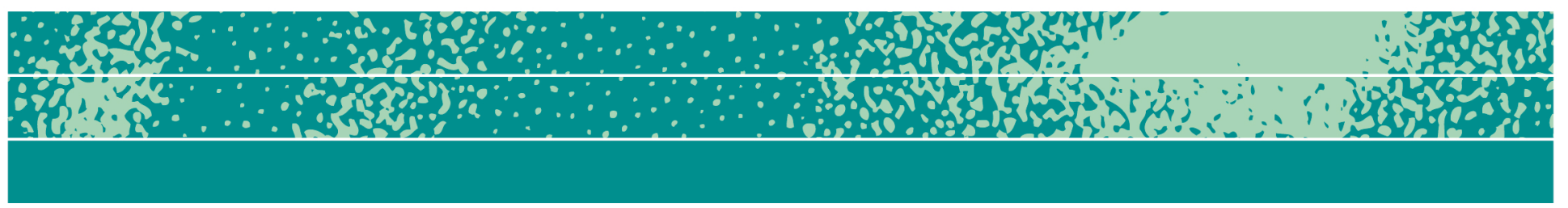

\section{The (Re)making of Flow: Mediator Companies and Knowledge Production}

\author{
Torbjörn Friberg
}

\begin{abstract}
This article concerns the (re)making of the flow of knowledge by structural biologists employed in a mediator company located between the university domain and the business world in Sweden. Drawing on Marilyn Strathern's theory of 'cutting the flow', this article ethnographically studies the flow of knowledge: how it is locally made, stopped, and remade in the laboratory. The first part reflects on the author's learning process during the fieldwork, while the second part discusses the hybrid position of mediator companies and the practices of associated researchers. The third part investigates the status of these companies among policymakers and life science stakeholders. The fourth and fifth parts ethnographically describe the cut and the (re)making of the flow of knowledge in everyday laboratory work. Taken together, these five parts will result in an attempt to extend Strathern's theoretical approach.
\end{abstract}

\section{Keywords}

Flow, Knowledge production, Mediator companies, Hybridity, Strathern
Page 1 of 19

JBA 6(2): 199-217

Autumn 2017

(C) The Author(s) 2017

ISSN 2245-4217

www.cbs.dk/jba 


\section{A hybrid production space}

This article is about the (re)making of the flow of knowledge in the hybrid production space between the public university domain and the private business world. I will examine the production of knowledge as it is (re)made in the laboratory by structural biologists who are employed in a mediator company. Ethnographically studying the flow of knowledge how it is locally made, stopped and remade - will enable improved understanding of the process, which seems to be of great significance in the literature concerned with flow (see e.g. Hannerz 1992, Appadurai 1996, Rockefeller 2011, Urban 2016). The questions to be asked then are: How do we recognise flow? In what sense is flow being cut, and how do people deal with such cuts? What can we theoretically learn by studying the (re)making of the flow of knowledge in the laboratory?

In response to the questions above, Marilyn Strathern's (1996) remarkable and ambiguous problematisation of hybridity makes a relevant theoretical point of departure for this article. She argues that modern thought and practice, which separate human and nonhuman, were challenged during the technological development in the 1980s and the 1990s in line with the emergence of network theories. It follows that many westerners today tolerate links between various heterogeneous objects and subjects - what one usually calls hybrids - as events of continuous flows. Strathern argues that 'the very concept of the hybrid lends itself to endless narratives of (about, containing) mixture, including the constant splicing of cultural data in what a geneticist might call recombinant culturology' (Strathern 1996: 522). Her main theoretical concern, in this context, is the endlessness of flows (networks). Instead of taking endlessness for granted, she argues, we need to understand the possibilities of stopping flows - how networks are cut. In a rather complex manner Strathern finally comes to the conclusion that 'the prospect of ownership cut into the network' (Strathern 1996: 524, see also Strathern 2004: 51-67). It is ownership that put an end to the continuous flow within networks. The most obvious example of this 'cutting', Strathern argues, is when scientists who are part of a research network (as they build upon previous knowledge production) patent the object of the network's study. Patenting means excluding previously involved scientists, thus cutting the research network. Simply put: 'property disowns' (Strathern 1996: 531). Even though Strathern's article is a perceptive piece of theoretical work, the reader is not told what happens when it comes to the (re)making of the flow within hybridcommercialised academic worlds.

In this article, then, I will ethnographically study the (re)making of the flow of knowledge with the help of a specific mediator company located in Sweden. Mediator companies offer an interesting empirical resource for thinking about (re)making the flow of knowledge in the sense that they work on a contract basis for industrial clients while at the 
same time utilising the instruments of the academic world. The mediator companies seem to be a moderately thought-provoking expression of contemporary European innovation policy (see for example Horizon2020) that pays tribute to the heterogenisation of various objects and subjects. The mediator researchers are expected to become hybrids of new entrepreneurs and traditional researchers (cf. Etzkowitch 2005: 81, 85), working in an organisation that is folded into a kind of 'third space' (Edward 1996, Bhahba 1994). However, this kind of third organisational space is not to be seen as delimited by strict boundaries. As the ethnographic examples in this article will illustrate, the boundaries between the industrial worlds, the academic domains and mediator companies are occasionally blurred in everyday life, thereby constituting a noteworthy case of new production of knowledge.

The narrative of the article moves steadily through six points: 1) an ethnographical reflection about the phenomenon of flow of knowledge, 2) the mediator researchers and their hybrid companies, 3) the notion of the mediator researchers' possibilities to connect to the flow of knowledge in complex settings, 4) the making of the flow in the laboratory, 5) an integrated discussion between the cutting of the flow and mediator researchers' strategies of remaking the flow, and 6) the theoretical learning of the study of the flow.

\section{Methodological insights}

Before describing the mediator companies' complex setting and the mediator researchers' hybrid positions, I will briefly state my access, performance and strategy in the fieldwork - as a learning process when engaging with alterity in the world of science.

In my role as an ethnographer in 2014 , I looked for an entrance to the field of Big Science in the Öresund region, in the southern part of Sweden and the Copenhagen area in Denmark. I chose to do ethnography in this region because my research project was concerned with the politics and organisation of the construction of ESS ${ }^{1}$ and MAX IV 2 in Lund, Sweden. Many regional policymakers in Sweden and Denmark see these two high-tech research facilities as 'motors of regional growth' (Tillväxtmotor). It is not an exaggeration to claim that ESS and MAX IV are expressions of the new European innovation policy that honours collaboration between university researchers, industrial entrepreneurs

\footnotetext{
${ }^{1}$ The European Spallation Source (ESS) is to become a multidisciplinary research centre based on the world's most powerful neutron source. It is planned to be finished in 2019. http://europeanspallationsource.se

2 The MAX IV laboratory will support three areas of research: accelerator physics, research based on the use of synchrotron radiation, and nuclear physics using energetic electrons. Construction started in 2010 and the opening ceremony was scheduled for 2016. https://www.maxlab.lu.se
} 
and government policymakers (Hallonsten 2012, Kaiserfeld and O'Dell 2013).

With this in mind, I contacted the policymakers on the Swedish side of Öresund, and asked if it would be possible to interview them. They responded positively as they thought my research project was relevant to regional development. It soon became obvious that the policymakers working to promote ESS and MAX IV were quite busy with their daily work and were constantly participating in all sorts of network meetings. I asked if I could observe some of the network meetings, and I was given access to a broad and active network concerned with life science's future position in relation to the two research facilities. Once inside this network, I conducted participant observations in several meetings. Most of the participants of these network meetings were 'important players', as one of my key informants expressed it. This meant that the participants, most often, had influential and powerful positions - in Sweden as well as in Denmark - which is not something ethnographers usually encounter (cf. Cefkin 2010). ${ }^{3}$

It is within this kind of network that I first met the founder of a global mediator company, here called Bio-Sci. This particular mediator company had customers, colleagues and branches around the world. As indicated above, mediator companies link industries and universities, which is to be seen as their essential business model. I later ran into the founder of Bio-Sci at the yearly life science conference in Copenhagen. As I knew that an important foundation had given him and his colleague a commission to write a report about life science mediator companies' future role in relation to ESS and MAX IV, we began to discuss the issue. In this context, I asked him if it would be possible to conduct fieldwork at Bio-Sci. Most people within this field are open-minded, and he was no exception. We agreed that I would pitch my ideas and mail them to him. He told me, however, that it was 'up to the mediator researchers to decide if it would possible'. After some negotiations with one of the mediator researchers (Mia), I finally got an interview with her. Consequently, after a few more weeks I got access to the workplace of the mediator researchers - the office, laboratory, beam line and other places such as

\footnotetext{
${ }^{3}$ My study involves several sites and various data over a period of one year between 2014 and 2015. I have been participating in a two-year postdoctoral project at the University of Copenhagen. The CoNeXT project is a University of Copenhagen interfaculty collaborative project involving more than 30 senior researchers from five faculties (i.e., Humanities, Natural Science, Health, Law, and Social Science), addressing a wide range of research questions using a variety of methods. Across their disciplinary differences, CoNeXT scientists are researching the potentials of some of the largest science and technology infrastructure projects built today, i.e., a new X-ray synchrotron light facility (MAX IV) and a world-leading neutron facility (ESS) under construction near Lund, Sweden, in the Öresund region. The social-scientific team is following policy makers, other scientists and industrial partners involved in organising the two research facilities.
} 
the refrigerator room. I did my fieldwork in Bio-Sci between 2014 and 2015 , over a period of six months.

Because I had access to most of the mediator researchers' work areas, I had opportunities to learn about their likes, worries, problems and solutions in relation to laboratory practices (cf. Traweek 1992). Occasionally, however, there were also some ethnographic obstacles such as when there were big issues at stake. During these stressful periods the mediator researchers told me to 'stay home'. This was because the mediator researchers took me seriously; they wanted to take time and explain things in detail if necessary, which was simply not possible during the stressful periods at work. This was their way of respecting the ethnographic work. My point here is not to say that it would be ethnographically uninteresting to participate during these stressful periods. Rather, I am pointing to the social fact that I was respecting the mediators' wishes to be left alone. It is thus to be seen as an ethical issue rather than ethnographic one. When conducting fieldwork, I had excellent opportunities to ask all sorts of questions about the mediator researchers' work. Seeing me write in my notebook during discussions and observations did not make them uncomfortable because they did the same thing when doing their own research - the structural biologists, when working in the laboratory, were continuously writing down every step in their lab books. The fieldwork was, however, not easy for a social scientist who had been trained in a kind of socio-cultural language. The mediator researchers took me seriously as an ethnographer and in return they expected me to understand the structural biological language. To do so, I had to study textbooks of structural biology in order to get a hint of what they were talking about. As most anthropologists know, it takes a long time to learn a new language, no matter what it is. However, since I did not have enough time to learn the structural biological language fluently, I had to come up with a strategy to study 'science in action', as expressed by Bruno Latour (1987).

The development of my strategy came out of the mediator researchers' continuous movement and practices of connecting various apparatuses. By recalling Alfred Gell's (2006: 29-75) close reading of Strahern's peculiar anthropological project, I began thinking about how people were crafting semiotic systems. Might it be possible to make sense of the mediator researchers' daily practices in the laboratory as a kind of semiotic system? Doing ethnography in laboratories as an organisational field of specialised expertise always raises questions about what and how much to learn (Hine 2001). My strategy implied a shift, from focusing on what the structural biologists were saying to observing what they were doing - a shift of ethnographic gaze from mouth and language to hands and practices (Knorr Cetina 1999: 8-11). I began to work from the premise that materialities (apparatuses) were connected by various 
practices, which together constituted a semiotic system. Contemporary materialities and practices gave meaning in relation to what had previously been done in the semiotic system. Similar to how linguists study how signs and symbols become a significant part of meaningful communication, I was trying to make sense of how materiality (various apparatuses) and practices (such as pipetting) were made into a meaningful line of flow of knowledge. It soon became obvious that if the mediator researchers lacked knowledge of what had previously been done, or were hindered from constituting a meaning, they were most likely to confront 'a cut' in the semiotic system. As such, they somehow needed to remake the semiotic system. Crafting a semiotic system in this way, I argue, is about (re)making the flow of knowledge.

\section{Mediator researchers and mediator companies}

In order to provide for a contextual understanding in the discussion that follows, I will here describe the mediator researchers, that is, illustrate the mediator researchers' working conditions, discuss their disciplinary approach and explain those interests that surround their scientific results.

The researchers working within the mediator company I studied hold PhDs from different academic disciplines such as chemistry and biology. They are not from a homogeneous group of researchers, nor are they exclusively educated in Sweden. They come from all over the world, which means that the common language in the laboratory is English. Far from regarding this kind of heterogeneity as something problematic, the mediator researchers actually encourage a wide-ranging academic and cultural background as a sort of advantage that can be valuable, for example, when confronted with new challenges presented by customers. The researchers seem to be gathered upon the notion of collaboration within the company - acting as a 'trading zone' in the sense that they are exchanging various types of knowledge about instruments, theories and experiments (see Galison 1997). It follows that disciplinary or cultural historical belonging plays a minor role when they act as mediators between academia and industry.

As an ethnographer, one seldom hears about nostalgic memories from a previous time in life. With the main focus on the modernistic future, the mediator researchers told me that their current 'in-between position' is preferable to the academic one. The reason for this is related to the social fact that they are not forced to think about strategic academic positioning nor do they have to consciously engage in social hierarchic games as described in Pierre Bourdieu's Homo Academicus (1990). As such, it is possible to argue that mediator companies offer researchers (with PhDs) an alternative career opportunity - a third space where academic prestige and honour play a minor role in everyday life. 
However, this is not to say that mediator companies totally lack academic values. My point here is that academic values - honour and prestige - are to be seen as marginal compared to the delivery of a final product to customers. Because this is a hybridised space of non-commercial and commercial production, the values are still present but seem to play a different role. For example, when I was discussing various publication strategies and the writing of research articles, the mediator researchers underlined the dualistic fact that these practices are about marketing the company as well as doing what you are trained to do. As such, there are both commercial and social academic aspects to consider in this context (as will be discussed later, these aspects might have a tremendous influence on the (re)making flow of knowledge). I was further told that the research lines within mediator companies 'are better than in the academic world' in the sense that the mediator researchers are able to avoid the increasing publication pressure. Simply put, these researchers publish when they want to, if they publish at all. ${ }^{4}$

What kind of research are the mediator researchers doing? When discussing the issue of commonality between the mediator researchers, they emphasised that their main common practices are to be understood as structural biology. In the broadest sense, it means that they are concerned with life as a reductive form - most often invisible to the human eye - as expressed in the following textbook quotation:

We are surrounded by microbes, plants and animals that we can immediately recognize as living things. However, it is still difficult to provide a concise definition of what life is. Perhaps the most useful definition for the purpose of our book is that life is a unit capable of chemical activities, and which can reproduce and evolve. (Liljas et al. 2009: 4)

When studying life as chemical activities, the structural biologists (I followed) are doing crystallography, which is considered an experimental science. It consists of examining solid crystalline cells, understanding the law of expansion, external form, and inner (atomic) structure (Nationalencyklopedin 1995). As crystallography and its related technologies have lately become more sophisticated, contemporary crystallographers are able to study the chemical bonds that draw one atom to another. It follows that they can modify a structure and thereby change its properties and behaviour. As a core structural science it produces, for example, persistent knowledge concerning the structure of DNA and creation of protein in cells. It means that these types of knowledge(s) might contribute to the design of new commodities:

It permeates our daily lives and forms the backbone of industries

\footnotetext{
4 Paul Rabinow (1996: 25-27) has drawn attention to the notion of patenting and publishing in relation to various scientific and commercial strategies.
} 
which are increasingly reliant on knowledge generation to develop new products, in widely diverse fields that include agro-food, aeronautics, automobiles, cosmetics and computers as well as the electro-mechanical, pharmaceutical and mining industries. (UNESCO 2014)

It seems that there is increasing awareness when it comes to crystallography as an important science. The year 2014 was declared the International Year of Crystallography by the United Nations. UNESCO's home page, under the Science and Technology tab, states the following:

Although crystallography underpins all of the sciences today, it remains relatively unknown to the general public. That is one of the reasons why the United Nations General Assembly (UNGA) proclaimed 2014 as the International Year of Crystallography (IYCr2014), and requested UNESCO to lead and coordinate, with the International Union of Crystallography (IUCr), the planning and implementation of educational and capacity-building activities during the Year. (UNESCO 2014)

The notion of crystallography as underpinning all sciences, in combination with the commercial fact that its knowledge production makes possible new products in various markets, has raised a great deal of interest among policymakers and stakeholders concerned with research.

\section{Connecting to new flows of knowledge in the complex setting}

To (re)make the flow of knowledge, the mediator researchers first have to capture and connect to new flows of knowledge in the complex setting of the Öresund region. In concrete terms, it means that they need to look for customers who have an interest in developing their potential products within the hybridised production space of meditator companies. Here, I will argue that this particular complex setting needs to be understood as an uncertain situation that might limit the possibilities for making new semiotic systems in the laboratory.

Within the Swedish context, where I mainly conducted fieldwork, policymakers and life science stakeholders perceive mediator companies as important future potential players in regional economic and social development. As previously noted, this mainly depends on the economic and political facts of the ongoing emergence and construction of two Big Science ${ }^{5}$ research facilities in the Öresund region: ESS and MAX IV. The mediator companies are intended to primarily occupy a position between the two main types of research facilities, industrial and academic. The mediator companies are important in the sense that policymakers and

\footnotetext{
${ }^{5}$ See Steven Shapin's (2010: 165-173) reasoning on the organisational form and moral constitution of Big Science.
} 
stakeholders treat them as a contemporary hybrid functional apparatus for industrial users (paying customers) and academic users (who pay the mediator researchers for material and time if they function as user support), as well as for potential future users (commercial and noncommercial) of the research facilities. Currently, one of the most urgent questions concerning ESS and MAX IV is about how to attract users. Consequently, there are several networks (academic as well as industrial) that have made it their duty to attract the industrial world to the two research facilities. In a contextual understanding, it is possible to see the mediator companies as self-evident apparatuses of the new regional innovation policy, based on hybridisation of public and the private research. ${ }^{6}$

However, it should be noted that the socio-political field around ESS and MAX IV is complex, with a great many actors of various types. It seems that nobody really has a complete overview - the actors within this field might not always be aware of who is a potential enemy or friend, partner or rival. It is a blurred hybridised field without any natural boundaries between the public and the private spheres. In other words, it is a complex reality that demands high socio-political skills and sensitivity. When I as an ethnographer occasionally asked for 'the man or woman with the blueprint', people within the field would burst into laughter. The laughter seemed to indicate that it was an impossible task to grasp a holistic picture. Consequently, as the mediator researchers told me, 'suddenly we get competition from unforeseen directions'. They told me about a nation-wide state-owned company, here called, $\mathrm{X}$, that increasingly sees its role as mediating between the industrial world and academic life science research. When I later spoke to representatives of the state-owned company X, I was told that they venture to 'help the private sector to apply for governmental research funding through academic researchers'. The state-owned company X aims to connect academics and businesspeople - similar to what mediator companies are trying to do. This kind of unforeseen competition, however, creates a disturbance among the mediator researchers on a local level as it limits the possibilities to connect to new flows. In addition to this example, it is worth mentioning the rumour of the establishment of a molecular bioscientific node in the southern region of Sweden - close to ESS and MAX IV. As a life science research director tried to establish a connection between the national research centre located in Stockholm and the southern region, it was possible to listen to local responses from within the mediator companies. The reason for this local disturbance, again, depends on the social fact that 'the node' is viewed as a competitor to the mediator companies' business model, not least since the national research centre in Stockholm also wants to promote collaboration between

\footnotetext{
${ }^{6}$ See Paul Rabinow's (1996: 1-17) argument of conflicting values between applied and pure research concerning bioscience and innovations.
} 
industry and academia.

These two threats - the state-owned company X and the molecular bio-scientific node - have led the mediator companies to launch an appeal, protesting that they are facing unjust competition since it is very difficult to compete with these government-funded mediators. A managing director of a mediator company made clear in written form that the competitive field is primarily to be understood in terms of knowledge rather than price. ${ }^{7}$ For the mediator companies, the two threats are to be seen as a question of limiting the possibilities of connecting to new flows of knowledge. If other organisational forms are operating in similar hybridised spaces - between the public university and the private industry - they will, most likely, decrease the possibilities for the mediator companies to connect to new flows of knowledge in the complex setting.

\section{The making of flow of knowledge}

One of the first things that struck me as an ethnographer in the laboratory was the movement of the researchers' hands in the course of producing new knowledge. When the hands suddenly stopped moving for a second or so, it was possible to understand their alignment with the researchers' heads. This micro-pause in the work routine, I would argue, shows the connection between the hand and the head. It reminds us that the process of making things well, as Richard Sennett (2008) remarked, is about craftsmanship:

Every good craftsman conducts a dialogue between concrete practices and thinking; this dialogue evolves into sustaining habits, and these habits establish a rhythm between problem solving and problem finding. (p. 9)

Since it is difficult for an ethnographer to explain what a good craftsman is thinking about, I will mainly focus on the actors' practices. This approach is also to be considered in connection to Ian Hacking's (1983) reasoning that we need to circumvent the notion that researchers are discovering phenomena - focusing on the theories in the minds of the researchers - by concentrating on how things are made and stabilised.

\section{In the laboratory}

Wearing a white lab coat, Mia is setting up a rack with small yellow test tubes, from left to right, marking them with numbers from 1 to 22 .

Besides these 22 test tubes she is also preparing 'a preference' in order to

\footnotetext{
${ }^{7}$ To protect the privacy of the community, I have decided not to use the document as a reference.
} 
be able to compare with the samples. While everything is set, Mia controls the pipettes and then opens a transport cooler containing protein samples (liquid) in big test tubes, provided by the customer. Before transferring the liquid from the bigger to the smaller test tubes with the pipette, Mia checks her lab book, reviewing the notes describing what she did previously when working with this customer's project. It is important to note that the lab book is central when it comes to the structural biological practices since almost everything is written down in its pages. Almost every practice is documented in order to keep track of what was done previously. When time allows, the mediator researchers share their written notes by transferring them to an electronic version on the company's Intranet. Mia says that the mediator researchers constantly discuss how to work with customers' samples. This is related to the analytical fact that they are striving to be able to reproduce the research activity in the future. She says: 'It will, however, never be exactly the same.'8

Research results within biotechnology are quite difficult to reproduce due to variety of ways to calibrate instruments and construct experiments. In response to this problem of reproduction, a research survey report suggests the standardisation of conceptual aspects and common electronic lab books (see Muthian 2014). A structural biologist, Mia underlines, must understand the importance of being able to document every activity and to understand the logical notion of systematisation.

When Mia has calculated how much liquid ought to be transferred between the two sets of test tubes, she sets the pipettes to take up exactly the right amount. Shortly after she has filled the small yellow test tubes with liquid, Mia mixes red liquid into each one. Everything is done systematically and then documented in the lab book. It is a step-by-step activity. Then, from the rack, she pipettes to a 96 well PCR plate in reverse order. When I ask her why she has reversed the order, she explains that it has to do with the reading of the apparatus later on. While she finishes with the yellow test tubes, she places them, one by one, on a different row on the rack. Again, it is done to avoid mixing 'finished with unfinished objects', she explains. When finally the PCR plate is complete, Mia covers the wells with a sealing mat to protect the liquid (protein) from light as well from other forms of liquid. Mia says, 'It is very important to think about how you move things from one place to another. You need to find a system that suits you, which makes the work easier. It is important to focus on what you are doing in order to avoid becoming bored.'

Having explained this, Mia stands up. I follow her to the

\footnotetext{
${ }^{8}$ Steven Shapin (2010: 85) notes that: 'In biology, and elsewhere in science, the search for the Truth about Nature has been taken over by a search for results that can be reliably manufactured in the laboratory.'
} 
centrifuge, in which she places the PCR plate. 'It will spin one minute at 200 G,' she says. From the centrifuge we move over to another apparatus, in which she places the PCR plate. Mia explains that this heating machine is connected to the computer standing next to it. The apparatus will heat up the protein samples and give her information about the melting curves. When we return to the machine after a while, she shows me Scurves on the computer screen. 'It is a special software for calculating the melting curves,' she explains. While, again, calculating and documenting in her lab book, Mia looks at the S-curves and decides where to measure them. She says that she is looking for the stabilising values, and that some of the S-curves are to be incorporated into the final report to the customer. By trusting her aesthetic gaze she makes her point that one can represent the S-curves in various ways. This is no problem as long as she gives an account of her approach in the final report. It might even be better for the customer to see the S-curves from different perspectives. Mia says that she is guessing that the customer is interested in knowing the level at which the protein stabilises. This is important knowledge if the customer plans to develop new medical drugs. She says, 'I do not really know what they are after, but I can make a qualified guess.' She later crafts a reference curve in the Excel program on the computer, while comparing various numbers and figures. When she is satisfied with the result, Mia copies the finished reference curve from Excel and pastes it into the report, explaining that the customer can now understand her interpretation of the S-curves as stable or unstable if they compare her arguments with the reference curve. She explains that it is important to look into the contract established with the customer in order to find out what is 'relevant information to include in the report'. She looks at me and says, 'Just like you, for me it is important to get the story straight. It is essential to tell a coherent story to the customers.' I ask her if she will personally hand over the report, face to face. Mia clarifies that the customers are too busy to meet in person, and that she will send the report by e-mail. This is how it is usually done, I am told.

The ethnographic description explains the making of the flow of knowledge in terms of craftsmanship in the laboratory. As described, the mediator researchers are building on what has previously been done with the object of study (here, protein) - there is, so to speak, always a kind of heritage from previous practices and various types of apparatus. With this in mind it is possible to argue that the mediator researchers are crafting a semiotic system as they connect various types of apparatus with the help of laboratory practices. For example, the pipetting (as a practice) connects the rack and the PCR plate (as material things) in a meaningful way. This is how the flow of knowledge is made and stabilised in the laboratory. Now, we will take a closer look at some problematic aspects that cut the flow of knowledge and the following remaking strategies. 


\section{The cut and the remaking of flow}

Following this discussion of the making, this part will examine the cut and the remaking of the flow of knowledge. I will argue that the cut in the third space - between business and academia - is constituted by a potential twoness, that is, commercialisation (the process of introducing something into commerce) and socialisation (the process of connecting to others).

\section{Commercialisation and socialisation}

As former PhD students trained at various universities around the world, the mediator researchers have impressive global social networks. Some of their former colleagues or collaborative partners (whom they occasionally meet at international conferences concerned with structural biology) are now turning to the mediator company as paying customers. Belonging to three communities thus opens up continuous possibilities. However, it also comes with problems. One problem in this context is when business customers ask for analyses of their own protein samples. When a customer delivers ready-made protein samples in a transport cooler there is a predetermined 'cut' in the flow of knowledge. Since the organic object of study (protein) is made elsewhere and owned by somebody else (the customer), the mediator researchers will encounter problems. Because the object of study is a potential innovative business, the customer will be reluctant to disclose their future intentions or share information on how they grew the protein in their laboratory.

As has been explained, the flow of knowledge is to be understood in terms of a semiotic system, that is, the object of study only gets its meaning in relation to the knowledge of how it was previously related to various practices and apparatuses. When they receive protein samples from a customer, the mediator researchers somehow need to remake the flow of knowledge: they need to figure out how the customer treated the protein samples. As the mediator researchers explained, 'It is not always easy to figure out what has been done previously.' At times, I heard that they had received 'cryptic data'. Most often they are able to make 'qualified guesses based on experience' with other researchers', but when there is inadequate information about the object of study, the mediator researchers need to contact the customer to request more information. Alternatively, they sometimes look for relevant information in research

\footnotetext{
${ }^{9}$ As Gregory Bateson (2000: 413) wrote: 'To guess, in essence, is to face a cut or slash in the sequence of items and to predict across that slash what items might be on the other side.'
} 
articles. This, however, is not unproblematic, as Mia explained:

It can be tricky to reproduce published results such as crystallization condition since it is not described accurately enough in the papers or it is simply not working the way it is described in the papers or it is simply not working the way it is described for some unknown reason. Also, it can be cumbersome to get access to all recent publications since only free-access journals are accessible to researchers outside the university (the price for each paper can be ridiculously high - a few hundred SEK, 32 for a Nature paper that I needed yesterday). Again, you can only get the papers by having connections inside the university (spouse, colleagues with double affiliations etc.).

Research publications might be helpful, but accessing them will almost certainly be too expensive for the mediator companies (commercial problems that can be solved by social relations).

Because the customers most likely want to patent the product in the end, the mediator researchers sometimes receive 'vague information'. Despite these business-related social facts, the mediators somehow need to remake the flow in order to be able to deliver a conclusive product to the customer. The quality of the protein and the success at enabling the flow of knowledge production will affect how much the mediator company will get paid (if the two parties have not agreed otherwise in the contract). This is why it is important to socially figure out how the protein was previously treated by the customers. Meanwhile, this involves commercialised research with organic objects of study (such as proteins) and there is no objective guarantee of good results. The mediator researchers explained, 'It is always a question or discussion concerning who will carry the risks'. This explanation seems to take us back to crystallography as an experimental science - structural biologists as contemporary craftsmen are unable to know the outcome in advance. ${ }^{10}$

\section{Socialisation and commercialisation}

Another problematic aspect to throw light on is related to situations wherein mediator researchers are using university-owned research facilities, instruments or apparatus. Against the background of a complex local history, the mediator company Bio-Sci is located within the research facility. Without going into historical details about the emergence of the mediator company, my point is that the mediator researchers in this

\footnotetext{
10 It will, however, be noted that structural biology (according to the mediator researchers' statements) has become more standardised in the last decades. But as Kaushik Sunder Rajan (2006: 293) argues: 'Protein crystallization has always been one of the hardest things to do in biological research and is often considered more of an art than a precise science.'
} 
company are already socially entangled in academic research networks, even though they belong to the hybrid business world. I was told that 'one is in but not really' by the mediator researchers. This 'in but not really' third-space situation can be illustrated with reference to an occasion when cake was being served at the research facility. When I entered the canteen together with the mediator researchers that day, we saw that everybody there was eating cake. I asked the mediator researchers if they would have a piece of cake as dessert. They looked at me and explained that that would be inappropriate, since they were not actually employed by the research facility, even though they were working there in situ. I was informed about the difference between mediator companies as businesses and the others as academic members. As we were sitting in the canteen, however, an academic structural biologist (employed at the research facility) came over and invited us to have a piece of cake - and we gladly accepted.

My point here is to show the social complexity of the mediator company's position. The mediator researchers know most academic researchers connected to structural biology or crystallography: the academic researchers are often former colleagues or new researchers who share the same interests. The social boundaries are blurred. Some of the owners of the mediator company even have tenured posts at the university while running a commercial business on the side - which is not unusual within life science in general, as I understand it. It follows that people are socially obligated towards each other in various ways (kinship, favours, expectations etc.). Having been socially entangled in the past with the academic researchers (who belong to the research facility and thus to the local university) opens up various possibilities for the mediator researchers, such as being able to ask for advice concerning the latest technology or knowing about a certain research issue. It occasionally also creates problems for mediator researchers who pay money for the use of various instruments and pieces of apparatus belonging to the university. Even though they are really paying customers, the mediator researchers are, more or less, socially treated as colleagues within the research facility. In view of the social circumstances, the mediator researchers seldom receive the technical service they are supposed to get as paying customers. As an ethnographer, I witnessed and heard about many similar situations, about how service managers 'had forgotten to prepare this or that'.11 In a more abstract sense, these social circumstances are about cutting the flow of knowledge. There are of course both advantages and disadvantages to being socially entangled when using the university's equipment, but my main point here concerns

\footnotetext{
${ }^{11}$ It seems that the problem of lack of good service is related to the fact that many service managers are busy with their own academic careers, that is, with their own research projects as they strive to secure a tenured position within academia.
} 
the problem that arises in making the flow of knowledge. Largely (but not exclusively) because of this social problematic aspect, the mediator researchers have begun to use other European research facilities with synchrotron light that offer remote control, that is, beaming crystallised proteins from a distance. The mediator researchers are thus able to control the beam line from their local office at home while at the same time they get 'first class technical support and service', I was informed. The mediator company sends their protein crystals via global delivery companies to other synchrotron facilities around Europe. At a time prearranged with the synchrotron facility, the mediator researchers gather around four computers with direct contact to service technicians and a robot that places the crystallised proteins in place for beaming. When I witnessed such an occasion, I became aware of the good and efficient service they received as paying customers.

In sum, the cut is constituted by a potential twoness: commercialisation and socialisation. Observed from the position of the cut, the remaking strategy is reversed. The commercialised cut of the flow (for example, when somebody else owns the object of study) is remade with the help of various social strategies, such as collective qualified guesses or by contacting the customer/owner. The socialised cut of the flow (for example, when friends or colleagues do not regard the mediator researchers as serious customers and thus refuse or forget to give them good service) is remade with the help of various commercialised strategies, such as the case when paying another research facility to help them with the job of making knowledge flow.

\section{A theoretical invitation}

The article took its theoretical departure from Strathern's reasoning of possibilities of cutting flow. Although I stressed that she highlights new and interesting questions, it seems that Strathern's approach needs to be developed when it comes to understanding and explaining the (re)making of flow. In this manner, I argued that mediator companies and mediator researchers - located in a third space - seem to be an interesting empirical resource for developing the notion of the (re)making of flow. In the following, I will first summarise the article's main points and then attempt to extend Strathern's theoretical approach.

The first point concerned how to ethnographically grasp the abstraction of the (re)making of flow of knowledge. I thus suggested that ethnographers could focus on the abstraction of flow as a way of crafting a semiotic system. The second point was based on the notion of giving the reader a general overview of the mediator researchers, their working conditions, disciplinary approach and some of the commercial interest of their scientific results - as an indication of the hybridity of commerce and sociality. Subsequently, the third point was about the complex setting in 
which the mediator companies try to connect to the new flows of knowledge - a way of arguing that their position in the third space is favourable, unique but problematic as it reveals new unforeseen competitors, that is, hybrid activities of public and private research domains. In order to understand the flow of knowledge, the fourth point described the everyday practices within the mediator company, Bio-Sci. The main point in this context was the process of crafting a semiotic system - understanding how various apparatuses were connected by different laboratory practices in a meaningful way. The function of this laboratory case was to illustrate the making of flow without any cuts. The fifth point took into consideration the cutting of the flow and mediator researchers' strategies of remaking the flow. This particular part illustrated that the cut in the hybridised third space is constituted by a potential twoness: commercialisation and socialisation.

So, how can Strathern's theoretical approach be extended, based on the ethnographic case of the third, hybridised production space? In order to answer this question, one possibility is to reconnect to Strathern's reasoning of the constitution of the cut (as presented in the introduction). According to Strathern, who mainly utilises western, commercial types of concepts, such as ownership, property and patenting, it seems that her main reasoning is concerned with some kind of commercial oneness. As Strathern's analysis is not crystal clear, I would like to interpret it and suggest that her reasoning, concerning the constitution of the cut, is about a commercialised oneness - such as the case when she is arguing that the cut is about ownership. If we take this abstract logic as true, then it is possible to argue that the constitution of the cut, in the third production space, is different in the sense that we are here dealing with a potential kind of twoness. As was noted in the ethnographic descriptions, the cut of the flow is constituted by the potentiality of 1) commercialisation (ownership) and 2) socialisation (friendship/collegiality). This kind of potential twoness could further be understood as having reversed remaking strategies. On the one hand, too much socialisation (friendship/collegiality) produces various commercialised strategies, such as the case of remote controlling the beaming of crystallised protein. On the other hand, too much commercialisation (ownership) creates social strategies, such as the circumstances concerned with qualified guessing among the mediator researchers, or when contacting the customers to request more information.

With the state of being two, I finally would like to claim, ethnographers in hybrid commercialised worlds might need to become alert about what kind of cuts and remaking strategies they are encountering in the field (cf. Pedersen 2013: 203). In a Strathernian sense (see 2006: 200), I hope that other ethnographers will receive this theoretical extension as an invitation rather than as an instruction - an 
opening for further problems rather than conclusive solutions.

\section{References}

Appadurai, A. 1996. Modernity at large: cultural dimensions of modernity. Minneapolis: University of Minnesota Press.

Bateson, G. 2000. Steps to an Ecology of Mind. Chicago: The University of Chicago Press.

Bhahba, H. 1994. The Location of Culture. London: Routledge.

Bourdieu, P. 1990. Homo Academicus. Stanford: Stanford University Press.

Cefkin, M. 2010. Ethnography and the Corporate Encounter. New York: Berghahn Books.

Edward, W. Soja. 1996. Thirdspace: Journeys to Los Angeles and Other Realand-Imagined Places. Oxford: Basil Blackwell.

Galison, P. 1997. Image \& Logic: A material culture of microphysics. Chicago: The University of Chicago Press.

Gell, A. 2006. The Art of Anthropology: Essays and Diagrams. Oxford: Berg.

Hacking, I. 1983. Representing and Intervening: Introductory topics in the philosophy of natural science. Cambridge: Cambridge University Press. https://doi.org/10.1017/cbo9780511814563

Hallonsten, O. (ed.). 2012. In Pursuit of a Promise: Perspectives on the political process to establish the European Spallation Source (ESS) in Lund, Sweden. Lund: Arkiv förlag.

Hannerz, U. 1992. Cultural Complexity. New York: Columbia University Press.

Hine, C. 2001. Ethnography in the laboratory. In Inside Organizations: Anthropologists at work, edited by David N. Gellner and Eric Hirsch, pp. 61-76. Oxford: Berg,

Kaiserfeld, T. and T. O'Dell. 2013. Legitimizing ESS: Big science as collaboration across boundaries. Lund: Nordic Academic Press.

Knorr Cetina, K. 1999. Epistemic Cultures: How the sciences make knowledge. Massachusetts: Harvard University Press.

Sunder Rajan, K. 2006. Biocapital: The Constitution of Post-genomic Life. Durham, NC: Duke University Press. https://doi.org/10.1215/9780822388005

Latour, B. 1987. Science in Action. Massachusetts: Harvard University Press. 
Liljas A., L. Liljas, J. Piskur and P. Nissen. 2009. Texbook of Structural

Biology. Singapore: World Scientific Publishing.

https://doi.org/10.1142/6620

Muthian, S. 2014. State of Translational Research Survey Report. Report, Sigma-Aldrich Corporation.

Nationalencyklopedin. 1995. Höganäs: Bokförlaget Bra Böcker AB.

Pedersen, M. A. 2013. The fetish of connectivity. In Objects and Materials: A Routledge Companion, edited by Gillian Evans, Elizabeth Silva and Nick Thoburn, pp. 197-207. London: Routledge.

Rabinow, P. 1996. Making PCR: A Story of Biotechnology. Chicago: The University of Chicago Press.

Rockefeller, S. 2011. Flow. Current Anthropology 52(4): 557-578. https://doi.org/10.1086/660912

Sennett, R. 2008. The Craftsman. London: Penguin Books.

Shapin. S. 2010. The Scientific Life: A Moral History of a Late Modern Vocation. Chicago: The University of Chicago Press.

Strathern, M. 1996. Cutting the network. The Journal of the Royal Anthropological Institute 2(3): 517-535.

https://doi.org/10.2307/3034901

Strathern, M. 2004. Commons and Borderlands: Working papers on interdisciplinarity and the flow of knowledge. Oxon: Sean King Publishing.

Strathern, M. 2006. A Community of Critics? Thoughts on New Knowledge. Journal of the Royal Anthropological Institute(N.S.) 12(1): 191209. https://doi.org/10.1111/j.1467-9655.2006.00287.x

Traweek, S. 1992. Beamtimes and Lifetimes: The world of high energy physicists. Massachusetts: Harvard University Press.

Unesco. 2014. Crystals shape our world.

http://www.unesco.org/new/en/natural-sciences/science-

technology/basic-sciences/infocus-bes/international-year-of-

crystallography-2014/

Urban, G. 2016. Corporations in the Flow of Culture. Seattle University Law Review 39: 321-351.

Torbjörn Friberg is associate professor of Social Anthropology at Malmö University. His research concerns the collaboration between universities (researchers), industries (entrepreneurs) and states (policy-makers). Friberg is presently working on the anthropology of the Triple Helix model in the context of the establishment and organization of two world leading research facilities - ESS and MAX IV - in Lund, Sweden. 